\title{
A THEORY OF LANGUAGE ACQUISITION IS NOT SO EASY
}

\author{
Wolfgang Klein \\ Max-Planck-Institut für Psycholinguistik
}

\begin{abstract}
The first part of this commentary discusses the minimal requirements that any serious theory of language acquisition must meet. It must take into account the particular properties of the human language processor and the (linguistic and nonlinguistic) input, as well as the specific motivation which causes the learner to apply the former to the latter. Neglecting, or even not keeping constant, some of these factors leads to a very distorted picture of the nature of language acquisition. In particular, claims about the difference between first (L1) and second language (L2) acquisition that ignore major variation in one of these components go astray.

In the second part, the articles of White, Clahsen, Gasser, and Tomlin are discussed. If it is true that Universal Grammar plays no role in $L 2$ acquisition, then, contrary to the claims made by those working in both areas, it can't play any role in L2 research, and thus L2 acquisition should look elsewhere for an appropriate theory. Connectionism, as suggested by Gasser, might be a place to look. At present, however, it is too unconstrained and more a descriptive language than a theory. Much in the spirit of Tomlin, it is argued that functions can indeed explain essential features of the acquisitional process. It is shown that the acquisition of the subject pronoun (and other referential devices) is essentially governed by functional rather than syntactical properties.
\end{abstract}

Let us not argue about the following points: (a) the study of second language acquisition (SLA) must aim for a theory-that is, a set of general principles under which the observed phenomena can be subsumed and from which other phenomena, unobserved as yet, can be correctly predicted; and (b) the capacity to acquire and to use a language is a species-specific genetic endowment. What is arguable, however, is what such a theory of SLA should look like, how it is related to a theory of first language acquisition, and what its position within a theory of intelligent behavior in general should be; as well as what the "innate language capacity" looks like; in particular, whether it is language-specific or even a grammar-specific component of our cogni- 
tive system or whether it is simply the application of general cognitive capacities to the particular field of language.

The four articles to be discussed here reflect three different views on these two questions. It will be helpful to begin this discussion with a glance at some of the facts which any account, no matter of what orientation, will have to deal with.

\section{SOME FACTS ABOUT LANGUAGE ACQUISITION}

Three components are inevitably present in any process of language acquisition. First, there must be some input-a representative specimen of the language to be learned. The amount and type of input may differ; it can be even presented in the form of metalinguistic descriptions; but without sufficient input, no one will learn a language. Second, a specific cognitive capacity is necessary. Pigs can hear as much English as one might imagine: they simply don't learn it. And third, there must be a reason to apply this marvellous capacity to the input-there must be a motivation. Theories of language acquisition tend to neglect this latter component, although it plays an important role in language teaching. But depending on the reason why you try to acquire a language, this process and the final result can look very different. When you are driven by the (not necessarily conscious) wish to become a normal, unperspicuous member of some social community, you had better replicate its speech habits as accurately as possible. When you only want to make yourself understood during a journey in a foreign country, there is no need to invest that much cognitive effort. I do not want to say, of course, that motivational differences alone are responsible for differences between first language (L1) and second language (L2) acquisition or different types of $\mathrm{L} 2$ acquisition. But any attempt to explain these differences that entirely ignores the role of motivational factors is bound to fail.

Consider now the input and its role in L2 and L1 acquisition. The input is roughly comparable, although still different, in the case of L1 and L2 acquisition outside the classroom. In both cases it consists of "real communication," i.e., namely, sound waves articulated in a particular context. But the situation is normally very different for that form of $\mathrm{L} 2$ acquisition which is the result of explicit teaching. Teaching provides the learner with vast amounts of negative evidence (often in red ink), in contrast to the limited negative evidence found in $\mathrm{L} 1$ and untutored L2 acquisition. Furthermore, teaching provides the learner with explicit grammatical rules he or she has to "internalize." Whatever this process of internalization may be, it is surely a cognitive process quite different from working on sound streams heard in a communicative context. Hence, any claim about the nature of L2 and L1 acquisition and their interrelationship that does not carefully isolate these different cases is bound to fail.

Both points seem obvious, and they are not new. I am mentioning them here because two of the four articles, White's and Clahsen's, discuss possible theoretical accounts of $\mathrm{L} 1$ and $\mathrm{L} 2$ acquisition and their interrelationship. No such comparison is reasonable, if the two factors-"type of input" and "type of motivation"-are ignored. Minimally, these two major sources of variation must be kept constant. This is not a particular requirement for theories of acquisition, it is just the normal logic of scientific research. If this were done, one would not have anything like a theory of L2 (or L1) 
Table 1. Language learning capacities

\begin{tabular}{|c|c|c|}
\hline \multicolumn{2}{|c|}{$\begin{array}{c}\text { Biological } \\
\text { Determinants }\end{array}$} & \multirow{2}{*}{$\begin{array}{l}\text { Available } \\
\text { Knowledge }\end{array}$} \\
\hline Peripheral & Central & \\
\hline $\begin{array}{l}\text { auditory } \\
\text { articulatory } \\
\text {..... }\end{array}$ & $\begin{array}{l}\text { memory } \\
\text { thinking } \\
\text { language module? } \\
\text {..... }\end{array}$ & $\begin{array}{l}\text { world knowledge } \\
\text { already existing } \\
\text { knowledge of language } \\
\text { to be learned } \\
\text { knowledge of other } \\
\text { languages }\end{array}$ \\
\hline
\end{tabular}

acquisition, but at least, one would have a legitimate base of comparison. Unfortunately, nothing to this effect is done.

Let us now turn to the last indispensable component-the language learning capacity proper. What constitutes this capacity? It seems obvious to me that, at any point during the acquisition process, learners can draw on two types of resources (see Table 1). There are, first, their biologically given faculties to process language; these include peripheral capacities (such as hearing and articulation) and central capacities (such as memory, thinking, and maybe others in, perhaps, some language-specific subcapacity). The distinction between peripheral and central is not always straightforward, and there is also a strong interaction between them; but this does not concern us here. And there is, second, the "available knowledge," that is, all the knowledge on which the learner can draw at that time. It includes knowledge of the world and the course of events in this world, but also everything the learner knows at that time about the language to be learned; it may also include knowledge of some other language.

One may have different ideas about what these components look like, how they interact, and what their relative weight in the acquisition process is. But there cannot be any doubt that they all play at least some role in this process. Hence, any serious theory of language acquisition, L1 or L2, has to take them into account.

All of these components change over time, some slowly, and some faster. As we get older, some of our peripheral capacities decrease-and this is perhaps a major source of the problems which adult learners typically have with phonology and intonation. Our knowledge increases (on the average), and this allows us, and sometimes forces us, to perceive new information-such as utterances in a new languagein the light of what we already know. Thus, increasing knowledge leads to a different processing of the input, with positive and with negative effects. Transfer, positive or negative, is just a special case of this "knowledge-filtered processing." But so are later steps of $L 1$ acquisition. The knowledge accumulated so far influences further steps in acquisition. Again, this is quite obvious. And there is an obvious consequence. Any serious theory of language acquisition, L1 or L2, must treat the "language learning capacity" as a dynamic system which is constantly changing under the influence of 
what it is doing. We will have to see to what extent the views discussed later take this fact into account.

One part of our language learning capacities is that innate part of our cognitive endowment which is responsible for language acquisition (and use). What does this subcomponent look like, and how does it change over time? More specifically: Is it different for first and for second language learners? It clearly includes "general" cognitive capacities such as memory, reasoning, and so on, and it is generally assumed that these change over the lifespan; but it is not easy to say how and when. In any event, some differences between $\mathrm{L} 1$ and $\mathrm{L} 2$ acquisition could be caused by such changes in our general cognitive system; our capacity to store new information may get worse, or our average attentiveness may deteriorate. We shall return to this point later. One might ask now whether our innate cognitive endowment also includes a "language module"-that is, a subcomponent which is specifically designed to handle language and its acquisition-or whether the various cognitive capacities that distinguish the human species from all other species are also completely responsible for that late and remarkable achievement called language. This question is not easy to answer. But clearly, a theory of the human mind that does without such an extra module would be a far better theory than one that has to stipulate it. Such a theory would be more general and more parsimonious. It is no proof, of course, that there is no such extra module. But it would be deplorable if we had to make this assumption. Therefore, the rationale of any researcher with some sense for theory should be obvious. No such assumption must be made until we are forced into it by the empirical findings. This evidence must be very strong, since one would not like to sacrifice generality and elegance for some silly counterexamples which cannot be immediately accounted for. Moreover, the possibility to stipulate an extra language module always remains as a last resort.

These general remarks should be sufficient to set the stage for the following discussion. I will first discuss White and Clahsen, then Gasser, and finally Tomlin.

\section{THE UG-VIEW}

Both White and Clahsen commit themselves to a special innate language module called Universal Grammar (UG) and think that it plays an important role in L1 acquisition. UG is a set of abstract constraints ("principles") on the possible form of sentences. Many of these constraints allow for some variation: they include an "open parameter" which can take different values. In L1 acquisition the learner has to find out-by analysis of the input-which particular value the various parameterized constraints have in that language. Parameter setting does not cover all aspects of language acquisition; in fact, it only concerns some formal aspects of grammatical structure. So, it is at best a theory of grammar acquisition, and much empty discussion could be avoided by calling it so, rather than to speak of a "theory of language acquisition."

I will return to discuss whether the UG view is a tenable one for L1 acquisition later. The main question here is whether UG plays a significant role in L2 acquisition. Given the definition of UG, the question itself sounds somewhat awkward. Both White and Clahsen repeatedly say that "UG is (possibly) no longer available." What 
could this mean? UG is the set of constraints that apply to all natural languages and are somehow hard-wired in the human brain as a part of human genetic endowment. In the absence of any neurological evidence to this effect, it is not easy to specify how these constraints should decay in our brain, or become inoperative. A benevolent interpretation-which I will adopt here-is just to say that the parameterized constraints of L1 or of L2, as postulated by linguists, do not show any effect in the acquisitional process. This makes the claim testable-at least as long as experts agree what the parameterized constraints are. I assume that this is the case.

The key question is, then, whether UG is in this sense available to L2 learners as it is supposed to be available to L1 learners. Here, White and Clahsen's views differ to some extent. Clahsen says it is not and presents some empirical evidence to that effect from his own work. White says that the issue is open and presents some evidence from others (against) and from her own work (in favor). Clahsen, in fact, mellows his "no" somewhat by saying that UG might be available "via L1," that is, to the extent to which it is encoded already in the learner's L1. Now, this is trivial. Denying it would mean that learners are even unable to transfer structural properties from their L1 to the L2. It would mean, for example, that if a learner's L1 has no mandatory subject pronoun ( + pro-drop), then this parameter setting will not be available to the learner's interpretation of the L2. So, Clahsen should not worry about this possible concession.

If it is true that UG plays no significant role in L2 acquisition, then it should play no significant role in L2 acquisition research. I share this view. A theory of L2 acquisition must be sought elsewhere. (I cannot offer such a theory-no one can-but I have some ideas in this direction; see, for example, Klein, 1986; Klein \& Perdue, 1988.) I fail to see, therefore, the logic of White's concluding remarks (pp. 131-132):

The question of UG accessibility in L2 acquisition is still unresolved. ... Although the main issue is still being researched, UG-based approaches to L2 acquisition have a number of important implications which hold true regardless of the final outcome. [UG cannot explain everything but only the acquisition of rather formal aspects of language structure.] ... Within this domain, UG provides a suitable framework or paradigm from which to address issues of importance within second language acquisition, a framework which gives new insights and suggests new lines of research.

I can't follow this. If UG plays no significant role in L2 acquisition, then it appears to me that the only new insight and the only suggestion for new lines of research is to try a different approach.

\section{A NOTE ON WHITE}

So far, I have treated White and Clahsen on a par. But as was said above, White herself is undecided about the key issue, and gives at least one piece of evidence in favor of UG being operative in $\mathrm{L} 2$ acquisition, too. It stems from her own work on Subjacency in SLA. Subjacency is a general constraint on various types of movement which forbids moving an element over more than one "bounding node." The definition of bounding node may vary within limits from language to language-it constitutes a 
parameter. French, for example, allows movements which English does not tolerate, and this different parameter setting is used as a test case here. Note that the important-and also appealing-feature of Subjacency (and other parameterized principles) relies on the fact that they are general constraints on different types of movement, like movement out of complex NPs, out of wh-islands, and others; whence its possible theoretical power. White (1988) tested three groups of French-speaking learners of English (and a control group of native speakers)-advanced adults, less advanced adults, and adolescents with little teaching (the latter group as well as the control group are not mentioned in her present article). The task consisted (mainly) in grammaticality judgments of (a) sentences which are deviant both in French and in English, and (b) sentences which are correct in French, but-due to a different parameter setting-not in English. She sums up the results as follows (p. 131):

\begin{abstract}
Both groups showed considerable accuracy on complex noun phrase violations sentences. In these sentences, parameter resetting is not at issue; they are ungrammatical in both languages.... However, in the case of $w h$-island violations, where the bounding status of $S$ is at issue, there is a significant difference between the two experimental groups; the low intermediate group failed to reject structures where a $w h$-word had been moved out of a $w h$-island. These results suggest that English is being treated like French in not having $S$ as a bounding node; namely, the Ll value of the parameter for the bounding nodes for Subjacency has been adopted. Subjects in the high intermediate group, on the other hand, accurately rejected these sentences, suggesting that they had reset this parameter and were treating $S$ as a bounding node in the L2. If so, the accessibility of UG is supported, given that appropriate information about the bounding status of $S$ is not available in the L1, and not easily inducible from the L2 input alone.
\end{abstract}

There are two problems here (above and beyond the problems already mentioned). One wonders, first, what kind of information forces, or allows, the learner to reset the parameter, rather than simply stick to it, if it is not the L2 input. And second, the short account of the experiments given by White here is somewhat trimmed compared to the actual findings reported in White (1988). The full picture differs in several important respects. To mention but two:

1. The results of the various tests are highly inconsistent. This means that the learners must have reset their parameter for some kinds of movement, but not for others (see, for example, Tables 2 and 3 in White, 1988). But this destroys the very notion of Subjacency being a general constraint on various types of movement. If these results are correct, then they are strong evidence, not that a parameter is reset, but that the various types of movement are learned independently.

2. On some tests, native speakers score distinctly worse than the learners: "Unfortunately, the native speaker controls did not agree with the judgments in the linguistic literature" (White, 1988, pp. 159-160). This not only raises some suspicion concerning what is to be found in the linguistic literature, it also suggests that something might be wrong with the alleged generalization captured by Subjacency.

In conclusion, White's study does not show at all that a UG principle is operative in L2 acquisition. But it may help us to correct wrong assumptions of theoretical linguists, and this would indeed be a substantial contribution of $\mathrm{L} 2$ acquisition research to linguistic theory. 


\section{A NOTE FOR CLAHSEN}

Clahsen does not assign UG the same crucial beneficiary role in L2 acquisition which he assumes it has in $\mathrm{L} 1$ acquisition. This raises an interesting question. According to the UG view on L1 acquisition, there are structural properties in any language which the learner cannot attain on the basis of the input and general learning strategies alone. For these properties, innate structural constraints-that is, UG-must lend a helping hand. With the rights of a nonnative speaker of English, I will call such a structural property a "UG-only." It is somewhat in dispute what such a UG-only is. White, for example, mentions the distribution of personal versus reflexive pronouns ("him"/"himself"). Clahsen assumes that verb-position and subject-verb agreement in German are linked by a (parameterized) UG principle. I will not argue here about whether this is reasonable or not. It should be clear, however, that, if there is no such UG-only, then there is no need to stipulate UG as an essential component of language acquisition, and hence of language acquisition theory. Now, if UG is no longer available in L2 acquisition, then either no UG-only can be acquired by a L2 learner, or else UG-onlies can be learned without UG (for example, by some other part of our cognitive system). Clahsen chooses the second option-quite reasonably so. It would be a strange claim, indeed, to state that second language learners cannot learn the correct use of "him" versus "himself," or subject-verb agreement in German. In other words, UG-onlies are learnable without UG. This is not entirely impossible, since this particular cognitive faculty might be available only to adults. But what is this faculty that comes with age? Could it be that wisdom of which the Bible speaks: "And he grew in age and wisdom" (Luke 2:52)? Personally, I like the idea that we who have lost so much also gain something as we get older, at least sometimes. But liking that idea is one thing, and having evidence is another, and unless evidence is given that there is a cognitive capacity which allows adults to learn certain structural properties but is not available to children, there is no need to stipulate an extra language module $\mathrm{UG}$ in $\mathrm{L} 1$ acquisition.

\section{THE CONNECTIONIST SEDUCTION}

Nothing could contrast more with the arid, though not fog-free, heights of the UG view than the tropical jungle of connectionism, whose incessantly spreading activation has finally entangled language acquisition. While there is already hot debate about the connectionist approach to L1 acquisition (Pinker \& Prince, 1988; Rumelhart \& McClelland, 1986), L2 acquisition research is, as usual, some years behind. Gasser's 1988 work is, as far as I know, the first attempt in this direction, and his present article is more an invitation, both seductive and frightening, to enter this field. This makes it difficult to discuss. In what follows, I will confine my comments to some general points which I find attractive or problematic in this view.

To begin with, I like the answer which connectionism gives to that perennial problem of any type of research, which we might call the "ECE problem": Everything is connected to everything. The connectionist's answer is to connect everything to everything. This makes connectionist models extremely flexible; but it is also their 
main weakness. There is almost no in-built constraint. It is always possible to add another epicycle when the empirical facts suggest this. More generally speaking, connectionism is at present a language rather than a theory or set of theories (cf. Levelt, 1989, ch. 1). The aim of scientific research cannot be to simulate reality, or selected parts of reality, in the form of an abstract network; rather, it must try to reduce the phenomena to be accounted for to a minimal number of powerful, general principles whose interaction determines the world of observable facts. Connectionist models, even when they work, do not immediately provide us with such principles. They may give us the right output, but they do not give us a transparent picture of the world and the laws which rule it. It is one thing to build a functioning clock and another to develop a theory of time.

This, I think, is a general argument which one can raise against connectionism. Connectionists make models tick, but do not make us understand as yet what makes them tick. Turning now to SLA more specifically, we do not want just a network which, when fed with sufficient input in the form of sentences, provides us with the appropriate regular and irregular tense morphology. We want to know the principles according to which the human mind breaks down the sound stream into smaller parts, assigns structure and meaning to these, retreats from false generalizations, and the like. We want to know why a certain type of motivation leads to a specific outcome: why the wish to become a member of the society leads to accurate phonology, whereas the bare need to satisfy some communicative needs tends to lead to pidginized varieties; why L2 and L1 acquisition normally differ that much, and why L2 acquisition by adults is often so different from children's L2 acquisition; why a special way of teaching is highly efficient for some people, but less so for others; and so on. At present, I cannot see how connectionism would approach these questions, let alone answer them. But at the same time, one must not forget that connectionism is still in its beginnings, and that nothing excludes us from making generalizations over functioning networks rather than over observable phenomena directly. This remains to be seen.

There are also some aspects of connectionism that I find appealing indeed. First, connectionist models are very precisely defined, and hence testable. They either work or they don't work, and they can be changed in a controllable way so as to give a better fit to the intended output. This, I think, is a major advantage over all other existing approaches to L2 acquisition. Second, connectionist models of learning can handle messy input-and that is what learners in reality are faced with, and what the human language learning capacity is used for. (This does not guarantee, of course, that connectionist models deal with this messy input in the same way that human cognition does.) And third, connectionist models do have a real link to neurological research and, in fact, are partly inspired by some people's ideas of how the brain is organized. Again, this similarity might turn out to be a very superficial one, for no one really knows how the human brain works; but one can at least see how neurological evidence can be built into the model. As already mentioned, it is too early to judge the chances of connectionism in our field. There is no empirical work so far, and there are also some doubts of a more principled nature. Thus, I remain to be convinced that it leads anywhere, but it may. 


\section{FUNCTION AS AN EXPLANATORY FACTOR}

In contrast to connectionist approaches, all too much work in L2 acquisition goes under the label "functional," and it is one of the merits of Tomlin's article to sort out what is shared by the battalions in this camp and where they diverge. Since I am largely in agreement with what he says-including his critical remarks-the following will be more of an expansion rather than a critical discussion of the points raised by Tomlin.

There are two fundamentally different, though not unrelated, ways in which one can look at the functional side of language acquisition. They can be characterized by two key questions:

1. How does a learner acquire the correct function of some morpheme or construction?

2. What can functions contribute to explain the process of acquisition?

In order to learn English, learners must learn, among many other things, the morpheme -ing. They must not only pick up this morpheme from the input, but also learn that it has specific functions, in this case at least two: gerund and progressive (not really a new insight, I admit). The morpheme -ing is a very salient phenomenon in English, and it is also very frequent. It is no surprise, therefore, that learners, both in L1 and L2 acquisition, pick it up early and that it surfaces early in their production. Understanding its precise functions is a different problem, whose solution is influenced by many factors; for example, by the learner's L1 (in the case of L2 acquisition). German learners will never understand why one can say, "Knowing the solution, he was able to ...," but not "Since he was knowing the solution, he was able to ...." (I suspect that native speakers do not understand either.)

The way in which a learner works out the correct function of a morpheme, construction, or any linguistic device, is clearly an interesting, complicated, and primordial acquisition problem. It is also clear that the causes that lead learners to pick up a certain form or construction need not be, and normally are not, the same ones which eventually lead them to correctly understanding its function. The morpheme -ing in dancing, to go on with this example, is perceptually much more salient than the morpheme -ed in danced, and this is equally true for a German or a Russian learner of English. But the former is not familiar with the (grammaticalized) category of "aspect," whereas the latter is, and hence will probably have many more problems figuring out its function. The Russian learners, on the other hand, may in the long run be seriously misled by taking the English aspect distinction to be exactly the same as the one in Russian-which it is not (for a comprehensive study of these problems, see Bhardwaj, Dietrich, \& Noyau, 1988). I will not elaborate on this point here; it should be clear that the study of language acquisition cannot just be the study of when certain formal properties pop up in the learner's production. This is probably agreed upon by most researchers, although there are still studies that investigate the acquisition of negation or of personal pronouns without ever looking at the function of these devices.

So far, the study of functions in language acquisition is only a matter of covering 
all relevant aspects of language. But function may also be a major explanatory factor. Let me illustrate this with an example which will eventually lead us to Tomlin's "referential management": the acquisition of personal pronouns. They are a major expressive device in any natural language, and mastering them is an essential step in acquisition. For simplicity's sake, I will only consider subject pronouns (the argument extends naturally to other pronouns). They can be characterized by a number of distinct properties: phonological (often, they cannot carry main stress), morphological (in English, they are inflected for number, case, and-in the third person-for gender), syntactical (they all can function as a subject), and functional (roughly, they serve to refer to a person or an object). In the following discussion, I will be concerned mainly with the latter two properties.

Syntactically, the English pronouns-I, you, he-she-it, we, you, they-are a uniform class: they can occupy the subject position. Functionally, however, they split into two very divergent subclasses:

deictic pronouns (first and second person): refer to the present speaker, the present addressee, or to groups containing these; and

anaphoric pronouns (third person): maintain reference to a person or object referred to before.

This description is grossly oversimplified (third person pronouns can be deictic as well, there may be exclusive plural, etc.), but suffices for present purposes.

We may now ask whether the acquisition of personal pronouns is driven by their syntactical properties or by their functional properties. In the former case, they should show up as a uniform class; in the latter case, we would not necessarily expect this. Of particular relevance is this question in connection with the so-called pro-drop parameter. There are languages that can omit an explicit pronoun in subject position, like Latin or Italian, and others that cannot, like English or German. Generative linguists have assumed this feature to be a consequence of a more abstract property of languages, the pro-drop parameter, which-depending on how it is set in a particular language-determines a number of structural properties of that language. Which features these are is somewhat in dispute; mostly, non-obligatory pronouns, rich verb morphology, free word order, and that-clause extraction are supposed to follow from + pro-drop. The attractive aspect of "parameter setting" as an explanatory device in language acquisition is now the fact that, if one of the above features is acquired (by input analysis), then all of the others follow automatically. Clearly, this parameter treats subject pronouns as a uniform class: it goes for syntactic properties, not for function.

There are numerous studies on the acquisition of personal pronouns, both in L1 acquisition (see, for example, the surveys of different languages in Slobin, 1985) and in L2 acquisition (Bremer, Broeder, Roberts, Simonot, \& Vasseur, 1988; Klein \& Rieck, 1982 ), and the findings vary. But one point is blatantly clear: overall, deictic pronouns distinctly precede anaphoric pronouns, both in L1 and L2 acquisition (with the possible exception of SLA in the classroom, for obvious reasons: the two types are taught together). Hence, the learner, child or adult, does not treat personal pronouns as a uniform class; he or she acquires them according to their function. In other 
words, it is the function that drives the acquisitional process, not abstract syntactic properties. This is not to deny that syntactic properties may play a role; but it is at best a secondary one.

$\mathrm{L} 1$ and L2 learners agree that deictic pronouns come first. But there are some interesting differences, as well. Children occasionally confuse $I$ and you, whereas L2 learners do not. This is plausible. Children must first work out the basic notion of deixis, namely, the fact that one and the same person must be referred to by different words, depending on who is speaking, and, conversely, that the same word can refer to two different persons. This is a fundamental mechanism of all natural languages, which underlies many other expressions as well. People who already speak a language have this mechanism at their disposal; all they have to learn is its concrete form in the language being acquired. Hence, L2 learners may be mistaken with respect to some particular form, but they do not make mistakes with the fundamental mechanism of deixis. (This holds analogously for other deictic categories, as in spatial or temporal reference.) In other words, the acquisition task differs for L1 learners and L2 learners in one crucial respect, and this difference has immediate consequences. Acquisitional differences of this type have nothing to do with biologically determined changes in the learning capacity; they are a result of the different "knowledge states" in which the learner approaches the input.

This important point is confirmed by looking at third person pronouns, which (normally) maintain reference to some entity introduced before. They are part of the interlocutors' system of "referential management" (Tomlin, 1989, 1990, pp. 167-170) or "referential movement" (Klein \& von Stutterheim, 1985, 1987). Whenever a speaker has to refer to some particular entity, say a house he or she wants to buy, then the speaker has to make a choice among an array of NPs that could serve this function: a house-the house-that house-that one-it- $\emptyset^{\prime \prime}$ (and maybe others). This choice is governed by several factors. Tomlin discusses two of them, recency and episode boundaries (as a result of memory restrictions). There are others, for example:

uniqueness in context: "Peter and Mary were here. He asked ... " but not "Peter and John were here. He asked..."

status as topic of focus: Some pronouns cannot be focused, for example all clitic pronouns, zero pronouns, and English it.

foreground-background: the transition from background to foreground and vice versa often requires different devices than the transition within these categories (cf. von Stutterheim \& Klein, 1989).

The interplay between these and maybe other factors constitutes a highly complex mechanism of referential choice and movement, whose precise operation differs to some extent from language to language. But in one form or the other, it is present in all languages, and every fluent speaker must master it.

Children cannot be expected to have mastered this mechanism by the time acquisition begins. L2 learners can master it, however. What they still have to learn is the specific way in which the new language implements it: Does it distinguish between definite and indefinite NPs by specific article forms? or by position? How does 
it mark different types of maintained reference? Does it distinguish between focused and nonfocused pronoun forms? In a detailed study of $L 2$ acquisition by learners of different origins (Klein \& Perdue, 1988, in press), we found extreme sensitivity of all learners to the mechanism of referential management. In fact, this mechanism largely determines the acquisition of the nounphrase, including pronouns, and it has ramifications in many other areas of the grammar, for example word order. These findings are in a line with what Tomlin reports $(1990, \mathrm{pp} .167-170)$, although his way of analyzing referential management is somewhat different in detail.

Findings of this kind suggest the following view of language acquisition (see also von Stutterheim \& Klein, 1987). There are some fundamental functions of language that a speaker must master. He or she must be able, for example, to refer to a particular person or object in context, namely, in relation to what has been said before, what is visible in the situation, and what can be assumed to be known to the listener. Similarly, the speaker must be able to make clear when certain events happened, or where certain objects are: he or she must be able to express spatial and temporal relations in a given context (Becker et al., 1988; Bhardwaj et al., 1988). Furthermore, the speaker must linearize this and the other information, within and across utterances, in a way that is comprehensible to the listener. The way in which this is done varies, within limits, from language to language. In Ll acquisition, the learner must both work out these basic functions and acquire the particular means of the L1. In L2 acquisition, the basic functions are there and are brought to the new input. It is these functions, therefore, which drive the learner to break down parts of the input and to organize them into small subsystems, which are reorganized whenever a new piece from the flood of input is added, until eventually the target system is reached (or more or less approximated). Under such a conception of language acquisition, functions do not explain everything. Other relevant components are, for example, the kind of input offered to the learner, perceptual saliency, changing biological determinants, and others, and they, too, must be taken into account. So, this conception is not a theory. (I think we all should be a bit modest in using that term.) But it leads us to a more realistic picture of how acquisition works, and why it works in the way it does.

\section{CONCLUSION}

The acquisition of a language, be it first or second, is a fascinating, but also an extremely complex, phenomenon whose course and final result are determined by a number of interacting factors. The serious researcher in this field should carefully explore the full range of this process, try to isolate the various factors which govern it, characterize the way in which these factors interact, and eventually develop a theory which is able to explain it. In doing so, it is important to have an eye on what people in related fields think and claim about language and about human cognition in general. But this view should not be taken for granted. Jumping on the bandwagon of other disciplines which at present enjoy more scientific glamor will not get us closer to a theory of language acquisition. We should be modest enough to admit that at present we are still very far from such a theory, and proud enough to consider our 
work an independent and substantial contribution to a better understanding of language and human cognition.

\section{REFERENCES}

Bhardwaj, M., Dietrich, R., \& Noyau, C. (Eds.). (1988). Second language acquisition by adult immigrants: Final report (Vol. 75). Strasbourg: ESF.

Becker, A., Carroll, M., \& Kelly, A. (Eds.). (1988). Second language acquisition by adult immigrants: Final report (Vol. 4). Strasbourg: ESF.

Bremer, K., Broeder, P., Roberts, C., Simonot, M., \& Vasseur, M.-T. (Eds.). (1988). Second language acquisition by adult immigrants: Final report (Vol. 1) Strasbourg: ESF.

Gasser, M. (1988). A connectionist model of sentence generation in a first and second language (Technical report UCLA-A-88-13). Los Angeles: Computer Science Department.

Klein, W. (1986). Second language acquisition. Cambridge: Cambridge University Press.

Klein, W., \& Perdue, C. (1988). Second language acquisition by adult immigrants: Final report (Vol. 4). Strasbourg: ESF.

Klein, W., \& Perdue, C. (in press). The learner's problem of arranging words. In B. MacWhinney \& E. Bates (Eds.), The cross-linguistic study of sentence processing. Cambridge: Cambridge University Press.

Klein, W., \& Rieck, B. O. (1982). Der Erwerb der Personalpronomina im ungesteuerten Spracherwerb. In W. Klein \& J. Weissenborn (Eds.), Zweitspracherwerb (pp. 35-71). Göttingen: Vandenhoeck \& Ruprecht.

Klein, W., \& von Stutterheim, C. (1985). Text structure and referential movement. Unpublished manuscript, Max-Planck Institut, Nijmegen, the Netherlands.

Levelt, W. J. M. (1989). Speaking: From intention to articulation. Cambridge, MA: MIT Press.

Pinker, S., \& Prince, A. (1988). On language and connectionism: Analysis of a parallel distributed processing model of language acquisition. Cognition, 28, 73-193.

Rumelhart, D. E., \& McClelland, J. L. (1986). Parallel distributed processing: Explorations in the microstructure of cognition (Vol. 1). Cambridge, MA: MIT Press.

Slobin, D. I. (1985). The cross-linguistic study of language acquisition (Vols. 1-2). Hillsdale, NJ: Erlbaum.

Tomlin, R. S. (1989). Focal attention, activated memory and the referential management of discourse production. Eugene: University of Oregon, Department of Linguistics.

Von Stutterheim, C., \& Klein, W. (1987). A concept-oriented approach to second language studies. In C. W. Pfaff (Ed.), First and second language acquisition processes (pp. 191-205). Cambridge, MA: Newbury House.

Von Stutterheim, C., \& Klein, W. (1989). Referential movement in descriptive and narrative discourse. In R. Dietrich \& C. F. Graumann (Eds.), Language processing in social context (pp. 39-76). Amsterdam: NorthHolland.

White, L. (1988). Island effects in second language acquisition. In S. Flynn \& W. O'Neill (Eds.), Linguistic theory in second language acquisition (pp. 144-172). Dordrecht: Foris. 